\title{
A prospective study of serum calcium, uric acid, liver enzymes in pregnancy induced hypertension
}

\author{
Prasad Torkadi ${ }^{*}$, U P Dhavale ${ }^{2}$
}

${ }^{1}$ Associate Professor, 2 Demonstrator,Department of Biochemistry, Dr PDM Medical College, Amravati, Maharashtra, INDIA. Email: sathishkumard11@gmail.com

\begin{abstract}
Background: Pre-eclampsia is one of the most common causes of maternal and fetal morbidity and mortality. It is a systemic disease that affects about 5-7 \% of all pregnancies and is the most common, yet least understood disorder of pregnancy. It is a rapidly progressive condition characterized by high blood pressure, platelet aggregation, swelling of the lower extremities and protein in urine. Sudden weight gain, headaches and changes in vision are important symptoms. Materials and Methods: This case-control study was conducted at Department of Biochemistry, Dr PDM Medical College, Amravati(Maharashtra), India. Data was collected from 70 preeclampsia cases and 70 normal healthy pregnant mothers in the Dept. of Obstetrics and Gynaecology. We have selected 70 cases and 70 controls according to our convenience. Cases are pregnant women with preeclampsia and controls are normal healthy pregnant women. Results: The present study includes 70 cases with pregnancy induced hypertension and 70 controls with normal healthy pregnancy. Mean gestational age showed high significance with Mean \pm SD of cases at $36.38 \pm 4.19$ weeks compared to that of controls at $39.62 \pm 1.16$ weeks with a p value of $<0.001$. Mean gestational age showed high significance with Mean \pm SD of cases at $36.38 \pm 4.19$ weeks compared to that of controls at $39.62 \pm 1.16$ weeks with a $p$ value of $<0.001$. Conclusion: Based on the present study, as serum calcium and magnesium levels are low in preeclamptic mothers and considering the high prevalence of preeclampsia, nutritional conditions of pregnant women seems to be of prime importance. Pregnant women should be educated about nutrition during pregnancy and probable risks of inappropriate diet should be informed.
\end{abstract}

Key Words: Pre-eclampsia, fetal morbidity, hypertension, platelet aggregation.

\section{*Address for Correspondence:}

Dr. Prasad Torkadi, Associate Professor, Department of Biochemistry, Dr PDM Medical College, Amravati, Maharashtra, INDIA.

Email: sathishkumard11@gmail.com

Received Date: 12/09/2019 Revised Date: 02/10/2019 Accepted Date: 29/10/2019

DOI: https://doi.org/10.26611/10021221

\begin{tabular}{|l|l|}
\hline \multicolumn{2}{|c|}{ Access this article online } \\
\hline Quick Response Code: & Website: \\
\hline & www.medpulse.in \\
\hline
\end{tabular}

\section{INTRODUCTION}

Pre-eclampsia is one of the most common causes of maternal and fetal morbidity and mortality. It is a systemic disease that affects about $5-7 \%$ of all pregnancies and is the most common, yet least understood disorder of pregnancy. ${ }^{1}$ It is a rapidly progressive condition characterized by high blood pressure, platelet aggregation, swelling of the lower extremities and protein in urine. Sudden weight gain, headaches and changes in vision are important symptoms. Typically blood pressure elevations and pre-eclampsia occur in the late second trimester or third trimester. The pathophysiological mechanism is characterized by a failure of the trophoblastic invasion of the spiral arteries which may be associated with an increased vascular resistance of the uterine artery and a decreased perfusion of the placenta. ${ }^{2}$ The incidence is about $6 \%$ in primigravid women. Clinically pre-eclampsia is characterized by persistently elevated blood pressure of greater than $140 / 90 \mathrm{mmHg}$, proteinuria and oedema. It may be associated with complications like visual disturbances, oliguria, eclampsia, hemolysis, elevated liver enzymes,

\footnotetext{
How to cite this article: Prasad Torkadi, U P Dhavale. A prospective study of serum calcium, uric acid, liver enzymes in pregnancy induced hypertension. MedPulse International Journal of Biochemistry. November 2019; 12(2): 39-42. https://www.medpulse.in/Biochemistry/
} 
thrombocytopenia, pulmonary oedema and fetal growth restriction. Early detection and prompt management helps in reducing the complications of this condition. Despite its prevalence and severity, the patho physiology of this multisystem disorder is still poorly understood and its aetiology has not yet been fully elucidated. Environmental and nutritional factors may play a role in the aetiology of pre-eclampsia. ${ }^{3}$ The importance of proper nutrition prior to and throughout pregnancy has long been known for optimizing the health and well being of both mother and baby. Pregnancy is a period of increasing metabolic demands with changes in a women's physiology and the requirements of a growing fetus. The greatest impact of pre-eclampsia is in developing countries where it accounts for $20-80 \%$ of the strikingly increase maternal mortality. Pregnant women in developing countries have been reported to consume diets with lesser amounts of essential minerals and vitamins. An inadequate intake might be harmful not only for the mother but also for the growing fetus. ${ }^{4}$ Hypertensive disorders account for 40,000 maternal deaths annually. Due to this, methods to reduce the risk of hypertensive disorders in pregnancy have received considerable attention. Research is focusing on prevention rather than treatment. There is evidence that indicates a role for micronutrients supplementation in preventing some pregnancy disorders. Among these, increasing calcium and magnesium intake can reduce the risk of pregnancy induced hypertensive disorders. ${ }^{5}$ Low serum calcium may cause high blood pressure by stimulating parathyroid hormone and renin release and also by inducing vasoconstriction by increasing its level in vascular smooth muscle. Calcium might also have an indirect effect on smooth muscle function by increasing magnesium levels. Magnesium plays an important role in peripheral vasodilatation. However, the role of calcium and magnesium in pregnant women are still being discussed. The aim of this study is to measure serum levels of calcium, magnesium, uric acid and liver enzymes in pre-eclamptic pregnancy and to compare with those in normal pregnancy. ${ }^{6}$

\section{MATERIALS AND METHODS}

This case-control study was conducted at Department of Biochemistry, Dr PDM Medical College, Amravati(Maharashtra), India. Data was collected from 70 preeclampsia cases and 70 normal healthy pregnant mothers in the Dept. of Obstetrics and Gynaecology. We have selected 70 cases and 70 controls according to our convenience.

Cases are pregnant women with preeclampsia and controls are normal healthy pregnant women.

\section{Inclusion Criteria}

$>$ Pregnant females with a singleton pregnancy.
$>$ Age range between 18 and 35 years.

$>$ Gestational age: All women in the $3^{\text {rd }}$ trimester, the gestational period ranged from 30-42 weeks. Calculated from the first day of the last menstrual period.

$>$ No history of previous urinary tract troubles and no evidence of UTI.

$>$ Not diabetic.

The cases were selected on the basis of simple random sampling method. The study protocol was approved by the Institutional Ethical Committee and informed consent was obtained from the subjects under study.

Control Group: The control group were women who fulfill the same previously mentioned criteria, but who did not develop hypertension during the 3rdtrimester. They were all normotensive with a systolic blood pressure of $130 \mathrm{mmHg}$ or less and a diastolic blood pressure of $80 \mathrm{mmHg}$ or less.

Exclusion Criteria: In both cases and control groups, the exclusion criteria included pregnant females with disorders such as chronic renal disease, chronic hypertension, heart disease, gestational diabetes, molar pregnancy, intrauterine fetal death, urinary tract infection and twin pregnancy.

Laboratory Methods: The blood pressure was measured by the sphygmomanometer, while the patient was lying on a couch on her side. The reading should be $140 / 90 \mathrm{mmHg}$ and above-

The serum calcium, magnesium, uric acid and liver enzymes estimated using Erba Chem-5 plus semiautomated analyser.

Measurement of calcium in serum was done using Ortho Cresolphthalein complex one method (OCPC method).

Measurement of magnesium was done using Xylidyl Blue Method.

Measurement of uric acid was done using Modified Trinder Method.

Measurement of ALP, AST and ALT was done using enzymatic method.

Statistical Methods: All findings were tabulated and statistically analysed using paired t-test using SPSS version 16.0.Mean and SD were calculated for age, gestational age, parity, birth weight and all the biochemical parameters. Significant level was set as $\mathrm{p}<0.05$.Numerical variables were presented as Mean \pm Standard Deviation (Mean \pm SD), while categorical variables were presented as percentages. Continuous variables were compared using Student's ' $t$ 'test. Student's ' $t$ ' test with unequal variance was used to compare means between two groups at 5\% level of significance. Correlation analysis was done by using Pearson correlation analysis. 


\section{RESULTS}

The present study includes 70 cases with pregnancy induced hypertension and 70 controls with normal healthy pregnancy.

\section{Age Distribution in Study Population}

Mean \pm SD of age showed no significant difference with Mean \pm SD of cases at $22.62 \pm 3.61$ yrs. compared to that of controls at $23 \pm 4.04$ yrs. and a p-value of 0.62 .

\section{Gestational Age in Study Population}

Mean gestational age showed high significance with Mean \pm SD of cases at $36.38 \pm 4.19$ weeks compared to that of controls at $39.62 \pm 1.16$ weeks with a p value of $<$ 0.001 .

\section{Mean \pm SD values of Blood Pressure in Study Population}

Mean \pm SD of Systolic BP (151.6 $\pm 14.15 \mathrm{mmHg}$ vs. $109.7 \pm 7.14 \mathrm{mmHg})$ and Mean \pm SD of Diastolic BP $(100.5 \pm 14.32 \mathrm{mmHg}$ vs. $75.6 \pm 5.62 \mathrm{mmHg})$ of the preeclamptic group are significantly higher than the control group with a p-value of $<0.001$. The Mean \pm Standard deviation value of Calcium in pre-eclamptic women was significantly less than normal pregnant women $(8.6 \pm$ $0.86 \mathrm{mg} / \mathrm{dL}$ vs. $9.88 \pm 1.14 \mathrm{mg} / \mathrm{dL} ; \mathrm{p}<0.001)$ and statistically highly significant. The Mean \pm Standard deviation values of Magnesium in pre-eclamptic women was significantly less than normal pregnant women (1.93 $\pm 0.32 \mathrm{mg} / \mathrm{dL}$ vs. $2.27 \pm 0.25 \mathrm{mg} / \mathrm{dL} ; \mathrm{p}<0.001)$ and statistically highly significant. The serum uric acid in preeclamptic women was significantly more than normal pregnant women $(6.66 \pm 2.28 \mathrm{mg} / \mathrm{dL}$ vs. $4.51 \pm 1.18$ $\mathrm{mg} / \mathrm{dL}, \mathrm{p}<0.001)$. The Mean $\pm \mathrm{SD}$ of Alkaline phosphatase, AST and ALT were increased in cases compared to controls and are statistically highly significant $(\mathrm{p}<0.001)$. Calcium and Magnesium have shown a significant negative correlation with Systolic Blood pressure, whereas uric acid and liver enzymes have shown a significant positive correlation with systolic blood pressure.

Table 1: Mean \pm SD Values of Gestational Age in Study Population

\begin{tabular}{cccc}
\hline Study group $(\mathrm{N}=140)$ & PIH Cases $(n=70)$ & Controls $(n=70)$ & $p$-Value \\
\hline Gestational age at admission for delivery & $35.16 \pm 4.15$ & $38.14 \pm 1.14$ & $<0.001$ \\
\hline
\end{tabular}

Table 2: Mean \pm SD Values of Blood Pressure in Study Population

\begin{tabular}{cccc}
\hline Study group $(\mathrm{N}=140)$ & PIH Cases $(\mathrm{n}=70)$ & Controls $(\mathrm{n}=70)$ & $\mathrm{p}$-Value \\
\hline Systolic Blood Pressure (in $\mathrm{mmHg})$ & $151.6 \pm 14.15$ & $109.7 \pm 7.14$ & $<0.001$ \\
Diastolic Blood Pressure (in $\mathrm{mmHg})$ & $100.5 \pm 14.32$ & $75.6 \pm 5.62$ & $<0.001$ \\
\hline
\end{tabular}

Table 3: Mean \pm SD Values of Calcium and Magnesium in Study Population

\begin{tabular}{cccc}
\hline Parameter & PIH Cases & Controls & p-Value \\
\hline Calcium $(\mathrm{mg} / \mathrm{dl})$ & $8.6 \pm 0.86$ & $9.88 \pm 1.14$ & $<0.001$ \\
Magnesium $(\mathrm{mg} / \mathrm{dl})$ & $1.93 \pm 0.32$ & $2.27 \pm 0.25$ & $<0.001$ \\
\hline
\end{tabular}

Table 4: Mean \pm SD Values of Uric Acid in Study Population

\begin{tabular}{cccc}
\hline Biochemical Parameter & PIH Cases & Controls & $\mathrm{p}$-Value \\
\hline Uric Acid $(\mathrm{mg} / \mathrm{dL})$ & $6.66 \pm 2.28$ & $4.53 \pm 1.18$ & $<0.001$ \\
\hline
\end{tabular}

Table 5: Mean \pm SD Values of Liver Enzymes in Study Population

\begin{tabular}{cccc}
\hline Biochemical Parameter (IU/L) & PIH Cases & Controls & P-Value \\
\hline ALP & $180.7 \pm 48.32$ & $95.6 \pm 49.32$ & $<0.001$ \\
SGOT/ AST & $54.7 \pm 33.53$ & $25.09 \pm 7.34$ & $<0.001$ \\
SGPT/ ALT & $36.8 \pm 26.76$ & $18.43 \pm 10.40$ & $<0.001$ \\
\hline
\end{tabular}

\section{DISCUSSION}

The present study has shown that maternal total serum calcium levels are significantly lower in pregnancy induced hypertension than in normal pregnant women as shown in Table 3 with Mean \pm SD of $8.57 \pm 0.96 \mathrm{mg} / \mathrm{dL}$ in preeclamptic pregnant women and a Mean \pm SD of $9.88 \pm 1.38 \mathrm{mg} / \mathrm{dLin}$ controls with a highly significant $\mathrm{p}$ value of $<0.001$. These results are in accordance with the findings of Naser et al and Sendhav Sandip et al. ${ }^{7}$ The present study has shown that maternal total serum magnesium levels can be significantly lower in pregnancy-induced hypertension than in normal pregnant women as shown in Table 3 with Mean \pm SD of $1.93 \pm 0.34$ $\mathrm{mg} / \mathrm{dLin}$ pregnant women and a Mean $\pm \mathrm{SD}$ of $2.26 \pm 0.25$ $\mathrm{mg} / \mathrm{dLin}$ controls with $\mathrm{p}$-value of $<0.001$. This study was similar to the findings of previous studies by $\mathrm{C}$ Punthumapol et al, ( Sendhav Sandip et al, Zohreh Tavana et al and Handwerker SM et al, Khan AMC and Sullivanet al. ${ }^{8}$ ) The present study Mean \pm SD (Cases-6.66 $\pm 2.21 \mathrm{mg} / \mathrm{dL} /$ Controls $-4.51 \pm 1.18 \mathrm{mg} / \mathrm{dL}$ ) showed that mean uric acid levels are significantly higher in 
hypertensive patients when compared with controls as shown in Table 4. ${ }^{9}$ This finding is in accordance with the study done by Punthumapol C et al, Sendhav Sandip et $a l$, Sangeeta $\mathrm{N}$ et al and Cunningham $\mathrm{F}$ et al. But Thangaratinam et al concluded from a meta-analysis that uric acid level measurement in pregnant women is not a strong predictive factor. ${ }^{10}$

\section{CONCLUSION}

Based on the present study, as serum calcium and magnesium levels are low in preeclamptic mothers and considering the high prevalence of preeclampsia, nutritional conditions of pregnant women seems to be of prime importance. Pregnant women should be educated about nutrition during pregnancy and probable risks of inappropriate diet should be informed. Possibly, serial measurements of the serum uric acid and liver enzymes from early pregnancy can bring forward a selected group of high risk women for treatment. Thus, it can be concluded that Calcium and Magnesium can be evaluated at an early date so that such mineral deficiencies can be treated by appropriate Calcium and Magnesium supplements. Uric acid and Liver enzymes can possibly be used as biomarkers for identifying and avoiding adverse pregnancy outcomes by prompt intervention.

\section{REFERENCES}

1. Kozic JR, Benton SJ, Hutcheon JA, Payne BA, Magee LA, von Dadelszen P, et al. Abnormal liver function tests as predictors of adverse maternal outcomes in women with preeclampsia. J Obstet Gynaecol Can. 2011;33:9951004.

2. Baschat AA, Magder LS, Doyle LE, Atlas RO, Jenkins $\mathrm{CB}$, Blitzer MG. Prediction of preeclampsia utilizing the first trimester screening examination. Am $\mathrm{J}$ Obstet Gynecol. 2014;211:514.e1-7.
3. Alavi A, Jahanshahi K, Karimia S, Arabzadea N, Fallahi S. Comparison of serum calcium, total protein and uric acid levels between hypertensive and healthy pregnant women in an Iranian population. Life Sci J. 2012;9:485488.

4. Jaiswar SP, Gupta A, Sachan R, Natu SN, Shaili M. Lactic dehydrogenase:a biochemical marker for preeclampsia-eclampsia. J Obstet Gynaecol India. 2011;61:645-648.

5. Di Lorenzo G, Ceccarello M, Cecotti V, Ronfani L, Monasta L, Vecchi Brumatti L, et al. First trimester maternal serum PIGF, free beta-hCG, PAPP-A, PP-13, uterine artery Doppler and maternal history for the prediction of preeclampsia. Placenta. 2012;33:495-501.

6. Parra-Cordero M, Sepulveda-Martinez A, Preisler J, Pasten J, Soto-Chacon E, Valdes E, et al. Role of the glucose tolerance test as a predictor of preeclampsia. Gynecol Obstet Invest. 2014;78:130-135.

7. Yu CK, Smith GC, Papageorghiou AT, Cacho AM, Nicolaides KH Fetal Medicine Foundation Second Trimester Screening G. An integrated model for the prediction of preeclampsia using maternal factors and uterine artery Doppler velocimetry in unselected low-risk women. Am J Obstet Gynecol. 2005;193:429-436.

8. Practice ACoO. ACOG practice bulletin. Diagnosis and management of preeclampsia and eclampsia. Number 33, January 2002. American College of Obstetricians and Gynecologists. Int J Gynaecol Obstet. 2002;77:67-75.

9. van Oostwaard MF, van Eerden L, de Laat MW, Duvekot $\mathrm{JJ}$, Erwich J, Bloemenkamp K, et al. Maternal and neonatal outcomes in women with severe early onset preeclampsia before 26 weeks of gestation, a case series. BJOG. 2017;124:1440-1447.

10. Koopmans CM, van Pampus MG, Groen H, Aarnoudse JG, van den Berg PP, Mol BW. Accuracy of serum uric acid as a predictive test for maternal complications in pre-eclampsia:bivariate meta-analysis and decision analysis. Eur J Obstet Gynecol Reprod Biol. 2009;146:814 .

\section{Source of Support: None Declared} Conflict of Interest: None Declared 